\title{
Induction of apoptosis by (-)-gossypol-enriched cottonseed oil in human breast cancer cells
}

\author{
WEIPING YE ${ }^{1}$, HSIANG-LIN CHANG ${ }^{1}$, LI-SHU WANG ${ }^{1}$, YI-WEN HUANG ${ }^{1}$, SHERRY SHU ${ }^{1}$, \\ YASURO SUGIMOTO ${ }^{1,2}$, MICHAEL K. DOWD ${ }^{3}$, PETER J. WAN ${ }^{3}$ and YOUNG C. LIN $^{1,2}$ \\ ${ }^{1}$ Laboratory of Reproductive and Molecular Endocrinology, College of Veterinary Medicine, and \\ ${ }^{2}$ The Ohio State University Comprehensive Cancer Center, The Ohio State University, Columbus, OH 43210; \\ ${ }^{3}$ USDA Southern Regional Research Center, New Orleans, LA 70124, USA
}

Received September 2, 2009; Accepted November 10, 2009

DOI: 10.3892/ijmm_00000442

\begin{abstract}
Induction of apoptosis is one of the mechanisms of chemotherapeutic agents against breast cancer. In addition, recent studies have shown that diets containing polyphenolic components possess anticancer activities either in vitro or in vivo by inhibiting cell proliferation and inducing apoptosis. The aim of our study was to explore the effects of (-)-gossypolenriched cottonseed oil [(-)-GPCSO], a polyphenolic compound, on the proliferation of the breast cancer cell line MCF-7 as well as primary cultured human breast cancer epithelial cells (PCHBCEC). We investigated whether the mechanism of the effects of (-)-GPCSO was mediated via the induction of cell apoptosis and the regulation of $\mathrm{Bcl}-2$ gene expression at both the mRNA and protein levels. Our results showed that (-)-GPCSO inhibited the proliferation of MCF-7 and PCHBCEC in a dose-dependent manner. (-)-GPCSO (0.1 and $0.2 \%$ ) induced DNA fragmentation in both MCF-7 cells and PCHBCEC. (-)-GPCSO suppressed the expression of Bcl-2 at both the mRNA and protein levels in MCF-7 cells and PCHBCEC in a dose-dependent fashion. Our results suggest that the growth inhibitory effect of (-)-GPCSO on MCF-7 and PCHBCEC is due, at least partially, to the induction of cell apoptosis, which is mediated by down-regulation of Bcl-2 expression at both the mRNA and protein levels. It might be possible for (-)-GPCSO to be developed as a novel chemotherapeutic agent for breast cancer patients.
\end{abstract}

\section{Introduction}

Breast cancer is one of the most frequently diagnosed female cancers and is second only to lung cancer as the most common

Correspondence to: Dr Young C. Lin, Laboratory of Reproductive and Molecular Endocrinology, College of Veterinary Medicine, The Ohio State University, Columbus, OH 43210-1092, USA

E-mail: lin.15@osu.edu

Key words: breast cancer, apoptosis, Bcl-2, gossypol cause of death among women 60 years of age or older (1). It is estimated that one in eight American women will develop breast cancer in her lifetime, and approximately one third of women with breast cancer develop metastases and ultimately die of the disease.

The molecular mechanisms underpinning the actions of cancer therapeutics are multi-factorial (2). One important mechanism is the activation of an apoptotic response via modulation of the expression of apoptosis regulatory proteins in cancer cells. Apoptosis, also known as programmed cell death, is a normal process of cell turnover that is characterized by nuclear condensation and degradation of DNA into oligonucleosomal fragments (3). It has been shown that the evasion of apoptosis by human cancer cells may result in drug resistance (4). The mechanisms by which most chemotherapeutic agents induce cell death are not well understood, although chemotherapy, radiotherapy and hormonal treatments appear to mediate their effects, in part, by inducing apoptosis (5-7). As the first line used in breast cancer chemotherapy, tamoxifen has been reported to induce apoptosis (8). It was reported that tamoxifen increases the apoptotic index (AI) in breast cancers expressing estrogen receptor $\alpha$, and there is a significant increase in the AI after $24 \mathrm{~h}$ of treatment with ICI 182780 , which is a pure estrogen antagonist without agonist activity (9). Zhang et al claimed that tamoxifen induced time- and concentration-dependent down-regulation of Bcl-2 at both the mRNA and protein levels, but tamoxifen did not affect Bax, an anti-apoptotic Bcl-2 family member, Bcl-xL, a pro-apoptotic Bcl-2 family member, or p53 expression at the mRNA and protein levels (10). Regarding the second generation of selective estrogen receptor modulators, raloxifene has estrogen antagonist action in both the breast and uterus; it combines with E-cadherin/catenin to activate induction of apoptosis (11). The third generation of breast cancer chemotherapeutic agents, aromatase inhibitors, have recently been reported to be more effective than tamoxifen in treating breast cancer. Three aromatase inhibitors, letrozole, anastrozole and 4-hydroxyandrostenedione were shown to increase apoptosis by 14,13 and $11 \%$, respectively, after eight days of treatment in MCF-7 human breast cancer cells engineered to express aromatase (12). 
As the first anti-apoptotic gene identified in 1988, Bcl-2 originally was recognized through its involvement in the $t(14,18)$ chromosomal translocation characteristic of human follicular B-cell lymphoma (13). Hockenbery et al demonstrated that $\mathrm{Bcl}-2$ is an inner mitochondrial membrane protein, and its overexpression blocks the apoptotic death of a pro-Blymphocyte cell line (14). Several clinical investigations found that overexpression of Bcl-2 occurred in 40 to $80 \%$ of primary invasive breast carcinomas, depending on the methods of measurement and quantification (15-17). Furthermore, overexpression of Bcl-2 is associated with resistance to various anti-tumor agents (18). Down-regulation of $\mathrm{Bcl}-2$ expression via antisense Bcl-2 decreased breast cancer cell viability (19). Gibson and his colleagues reported that it might be feasible to target Bcl-2 expression for the improvement of the outcome of current standard chemotherapies in breast cancer (20).

Gossypol (GP), a polyphenolic compound naturally occurring in cottonseed (21), was first identified as a male anti-fertility agent in China (22). Recently, GP was found to have anti-proliferative effects against a diversity of human cancer cells lines, such as breast, ovary, prostate and colon (23-26). Of the two main forms, (-)-GP has been found to be more potent than racemic GP (23). It was demonstrated that the anti-proliferative effect of GP is mediated via induction of cellular apoptosis. Teng claimed that GP induced apoptosis in rat spermatocytes mediated by biphasic regulation of c-fos protein (27). It has also been shown that less than $5 \mu \mathrm{M}$ of GP induced DNA fragmentation in two human colon carcinoma cell lines HT29 and LoVo after exposures of 24 and $48 \mathrm{~h}$ (28). In addition, it was reported that GP has an apoptotic effect on human lymphocytes (29). Chang and his associates found that GP induced apoptosis in human alveolar lung cancer cell line A549 cells, mediated by up-regulation of Fas/ FasL (30). Xu et al found that (-)-GP enhanced the response to radiation therapy resulting in tumor regression of human prostate cancer (31). GP has been shown to induce apoptosis in human promyelocytic leukemia HL-60 cells through the reactive oxygen species-independent mitochondrial dysfunction pathway (32). Oliver and his colleagues found that (-)-GP binds to the BH3-binding groove of Bcl-xL and Bcl-2 protein (33). It has been shown that milk from cows fed a GP-containing cottonseed meal significantly inhibited the growth of MCF-7, multidrug-resistant MCF-7/Adr and RE-B2T rat esophageal carcinoma cells (34). Epidemiological data from independent countries of the former Soviet Union revealed that the human cancer incidence rates were significantly lower in countries using cottonseed oil (containing GP) as cooking oil for human daily food consumption than that of neighboring countries not using cottonseed oil $(35,36)$. Our preliminary study demonstrated that (-)-GPCSO, which is specifically developed by the USDA containing 65\% (-)-GP and $35 \%(+)-G P$ (equivalent to 10.6 and $5.6 \mu \mathrm{M}$ ), possessed more potent anticancer activity in human breast cancer cells than conventional cottonseed oil, which contains 35\% (-)-GP and $65 \%(+)-G P$. Therefore, it might be possible for (-)-GPCSO to be developed as a chemotherapeutic or chemopreventive agent. However, the effect of (-)-GPCSO on breast cancer cells is still unknown. In the present study, we investigated the mechanism of apoptosis induced by (-)-GPCSO in the human breast cancer cell line MCF-7 and PCHBCEC. Our results demonstrated that (-)-GPCSO significantly inhibited the growth of MCF-7 cells and PCHBCEC due, at least partially, to the induction of apoptosis through its down-regulation of Bcl-2 at both the mRNA and protein levels in two types of cells.

\section{Materials and methods}

(-)-Gossypol-enriched cottonseed oil. (-)-GPCSO was kindly provided by the USDA Southern Regional Research Center, (New Orleans, LA) and contained $\sim 65 \%$ (-)-GP, and 35\% (+)-GP. It was diluted $50 \%$ as a stock solution in the same volume of dimethyl sulfoxide (DMSO) and stored at $4^{\circ} \mathrm{C}$. Working stocks of (-)-GPCSO were freshly prepared before each experiment.

Cell culture. MCF-7 cells were cultured in phenol red-free high-calcium (1.05 $\mathrm{mM} \mathrm{CaCl}_{2}$ ) Dulbecco's modified Eagle's medium and Ham's F12 medium (DMEM/F12, Atlanta Biologicals, Lawrenceville, GA) supplemented with 5\% fetal bovine serum (FBS), and antibiotic-antimycotic (100 unit/ml penicillin G sodium, $100 \mathrm{mg} / \mathrm{ml}$ amphotericin B) (Gibco Cell Culture $^{\mathrm{TM}}$ ). PCHBCEC were directly isolated from human breast cancer tissues obtained through the Tissue Procurement Program of The Ohio State University, Arthur G. James Cancer Hospital in Columbus, $\mathrm{OH}$ and then cultured in low calcium $(0.04 \mathrm{mM} \mathrm{CaCl}$ ) DMEM/F12 supplemented with Chelex-100 (Bio-Rad Laboratories, Richmond, CA; cat. no. 142-2822)-treated FBS (10\%) following a previously described protocol (23).

Non-radioactive cell proliferation assay. MCF-7 cells and PCHBCEC were cultured separately in $100 \mu 1$ of either phenol red-free high-calcium DMEM/F12 medium supplemented with $5 \%$ FBS or low calcium DMEM/F12 medium supplemented with Chelex-100-treated 10\% FBS in 96-well culture plates at an initial density of $5 \times 10^{3}$ viable cells/well. After being cultured overnight, the medium was replaced with either DMEM/F12 medium or low calcium DMEM/F12 medium supplemented with $0.2 \%$ bovine serum albumin (BSA) and cultured overnight. MCF-7 cells and PCHBCEC were treated with $0.025,0.05,0.1$ and $0.2 \%$ (-)-GPCSO for $24 \mathrm{~h}$. Finally, cell proliferation was determined by measuring the optical density at $490 \mathrm{~nm}$ according to the manufacturer's instructions. Briefly, 3-(4,5-dimethylthiazol-2-yl)-5-(3carboxymethoxyphenyl)-2-(4-sulfophenyl)-2-H-tetrazolium (MTS) (Promega, Madison, WI; cat. no. G1111) was mixed with phenazine methosulfate (PMS) (Sigma, St. Louis, MO; cat. no. P9625-500MG) (20:1), and $20 \mu 1$ of mixture was added to each well and incubated for $1.5 \mathrm{~h}$. The color density was measured at $490 \mathrm{~nm}$ using a kinetic microplate reader (Molecular Devices Corp., Menlo Park, CA) and Softmax Pro software (version 2.1.1).

Cell morphology. MCF-7 cells $\left(1 \times 10^{5}\right)$ in DMEM/F12 medium containing 5\% FBS were seeded in a 6-well plate. After a $24 \mathrm{~h}$ culture, the medium was replaced with DMEM/ F12 supplemented with dextran-coated charcoal (DCC) (dextran T-70, Pharmacia; activated charcoal, Sigma)-treated $5 \%$ FBS. The MCF-7 cells were treated with $0.1 \%$ (-)-GPCSO, 
and photomicrographs were obtained following treatment of 0 and 24 h using a Olympus M021 microscope with a digital camera.

DNA fragmentation analysis. Cell culture and treatment were carried out as above. After 12 and $24 \mathrm{~h}$ treatment with vehicle control, 0.1 or $0.2 \%$ (-)-GPCSO, cells were collected, and the DNA fragmentation assay was performed using Quick Apoptotic DNA Ladder Detection Kit (Biovision, Mountain View, CA; cat. no. K120-50) (37). Samples were electrophoresed in a $1 \%$ agarose gel containing $0.5 \mathrm{mg} / \mathrm{ml}$ ethidium bromide. Images of the gel were obtained using a UV transilluminator and the Fujifilm LAS-3000 image system (Fujifilm Medical Systems USA, Inc., Stanford, CT).

Cell treatment, total RNA extraction and reverse transcription-polymerase chain reaction. $\mathrm{MCF}-7$ cells or PCHBCEC were seeded separately in $5 \mathrm{ml}$ of either DMEM/ F12 medium supplemented with $5 \%$ FBS or low calcium DMEM/F12 supplemented with Chelex-100-stripped $10 \%$ FBS in 6-well culture plates at an initial density of $1 \times 10^{5}$ viable cells/well. For MCF-7 cells, the medium was replaced with DMEM/F12 medium supplemented with 5\% DCC-stripped FBS. For PCHBCEC, the medium was replaced with low calcium DMEM/F12 supplemented with 10\% DCC and Chelex-100-treated FBS. After $24 \mathrm{~h}$, cells were treated with 0.05 and $0.1 \%$ (-)-GPCSO overnight, and then total RNA was extracted in $1 \mathrm{ml}$ Trizol ${ }^{\circledR}$ Reagent (Invitrogen) following the manufacturer's instructions.

RT-PCR was performed in a Mastercycler (Eppendorf ${ }^{\circledR}$ ). Briefly, after RNA concentrations were measured using the DU-70 spectrophotometer (Beckman Instruments Inc., Fullerton, CA, USA), $1 \mu \mathrm{g}$ total RNA was reverse transcribed with $200 \mathrm{U}$ M-MLV Reverse Transcriptase (Invitrogen) by incubating at $37^{\circ} \mathrm{C}$ for $50 \mathrm{~min}$ followed by $70^{\circ} \mathrm{C}$ for $15 \mathrm{~min}$ in the presence of $0.2 \mathrm{mM}$ dNTP (stock solution $10 \mathrm{mM}$ each dATP, dGTP, dCTP and dTTP at a neutral pH) (Invitrogen), $1 \mu \mathrm{M}$ Random Hexamer (Amersham), $10 \mu 1$ 5X First Strand Buffer (Invitrogen), $5 \mu 10.1 \mathrm{M}$ DTT (Invitrogen) and $1 \mu 1$ RNase Inhibitor (Invitrogen) in a total volume of $50 \mu 1$. PCR conditions were optimized for the $\mathrm{MgCl}_{2}$ (Invitrogen) concentration, annealing temperature and cycle number for the amplification of $\mathrm{Bcl}-2$ and $36 \mathrm{~B} 4$ in a gradient Mastercycler. For Bcl-2, $2 \mu 1$ of newly synthesized cDNA was used as a template for PCR. The PCR reaction mix consisted of $2.5 \mu 1$ 10X PCR buffer (Invitrogen), $2.5 \mathrm{mM}$ $\mathrm{MgCl}_{2}, 1 \mathrm{U}$ Platinum Taq DNA polymerase (Invitrogen), $0.24 \mu \mathrm{M}$ each primer and pure water to a total volume of $25 \mu 1$. The reactions were incubated at $95^{\circ} \mathrm{C}$ for $5 \mathrm{~min}$ followed by thirty cycles of amplification consisting of denaturation at $95^{\circ} \mathrm{C}$ for $1 \mathrm{~min}$, annealing at $60^{\circ} \mathrm{C}$ for $1 \mathrm{~min}$, and elongation at $72^{\circ} \mathrm{C}$ for $1 \mathrm{~min}$. A final incubation at $72^{\circ} \mathrm{C}$ for chain elongation was included. For 36B4, the reactants were incubated at $95^{\circ} \mathrm{C}$ for $5 \mathrm{~min}$, then 30 cycles of amplification were performed with each cycle consisting of denaturation at $95^{\circ} \mathrm{C}$ for $1 \mathrm{~min}$, annealing at $63^{\circ} \mathrm{C}$ for $1 \mathrm{~min}$ and extension at $72^{\circ} \mathrm{C}$ for $1 \mathrm{~min}$. The primer sequences for Bcl-2 were 5'-GTG AAC TGG GGG AGG ATT GT-3' (sense) and 5'-GGA GAA ATC AAA CAG AGG CC-3' (antisense), and for the housekeeping gene, 36B4, the sequences were
5'-AAA CTG CTG CCT CAT ATC CG-3' (sense) and 5'-TTT CAG CAA GTG GGA AGG TG-3' (antisense). The final products were mixed with $2.5 \mu 110 \mathrm{X}$ agarose gel sample buffer and $10 \mu 1$ were loaded per well in a $1.5 \%$ agarose gel containing $1 \%$ ethidium bromide. The specific bands were quantified by ImageQuant software (Molecular Dynamics, Sunnyvale, CA). The results are presented as the ratio of Bcl-2 to $36 \mathrm{~B} 4$.

Western blot analysis. Cell culture and treatment were carried out as described above. After $24 \mathrm{~h}$ of treatment, total cellular proteins were isolated using M-PER ${ }^{\mathrm{TM}}$ Mammalian Protein Extraction Reagent (Pierce, Rockford, IL), and protein concentrations were measured using the Micro $\mathrm{BCA}^{\mathrm{TM}}$ protein assay reagent kit (Pierce), according to the instruction manual. Twenty micograms of protein from each sample was separated using 4-15\% Tris-HCl Ready Gel (Bio-Rad Laboratories, Hercules, CA) and transferred onto a PVDF membrane (Millipore Corp., Bedford, MA). The membrane was blocked in 5\% non-fat dry milk in PBS containing $0.1 \%$ Tween-20 (PBS-T) at $4{ }^{\circ} \mathrm{C}$ overnight. Immunoblotting was performed with primary antibody Bcl-2 (1:500 dilution sc1517; Santa Cruz Biotechnology, Inc., CA, USA), or B-actin (1:1000 dilution sc-1615, Santa Cruz Biotechnology, Inc.) at room temperature for $1 \mathrm{~h}$ and then incubated with donkey anti-goat IgG-conjugated horseradish peroxidase (HRP) (1:1000 dilution, sc2020, Santa Cruz Biotechnology, Inc.) at room temperature for $1 \mathrm{~h}$. Bcl-2 and $\mathrm{B}$-actin proteins were visualized with a chemiluminescent detection system (ECL, Amersham Biosciences, Buckinghamshire, UK), and images were obtained using the Fujifilm LAS-3000 image system. The densities of specific bands were quantified by MultiGauge software (version 2.02). The results are presented as the relative protein expression by the ratio of $\mathrm{Bcl}-2$ to $\beta$-actin.

Statistical analysis. The results for the MTS assay are presented as the mean \pm standard deviation (SD) for four replicate culture wells as one treatment group. The results for the PCR reaction and Western blot analysis are presented as the mean \pm SD for three replicates per group. Statistical analysis was performed using SAS for Windows (SAS Institute Inc. Cary, NC). Statistical differences were determined using the Student's t-test for independent samples. p-values $<0.05$ were considered to be statistically significant.

\section{Results}

Inhibitory effects of (-)-GPCSO on proliferation of MCF-7 and PCHBCEC. It was previously reported that $( \pm)-G P$ and (-)-GP reduced the proliferation of primary cultured human breast cancer epithelial and stromal cells in a dose-dependent manner (23). In the present study, the effects of (-)-GPCSO on the proliferation of MCF-7 cells and PCHBCEC were evaluated by non-radioactive cell proliferation assay. (-)-GPCSO inhibited the growth of both MCF-7 cells and PCHBCEC in a dose-dependent fashion (Fig. 1). In MCF-7 cells, $0.025,0.05,0.1$ and $0.2 \%$ of (-)-GPCSO reduced cell growth to $15,18,47$ and $69 \%$ of the control, respectively. In PCHBCEC, the same concentrations of (-)-GPCSO decreased cell growth to $6,27,30,30 \%$ of the control, respectively. 


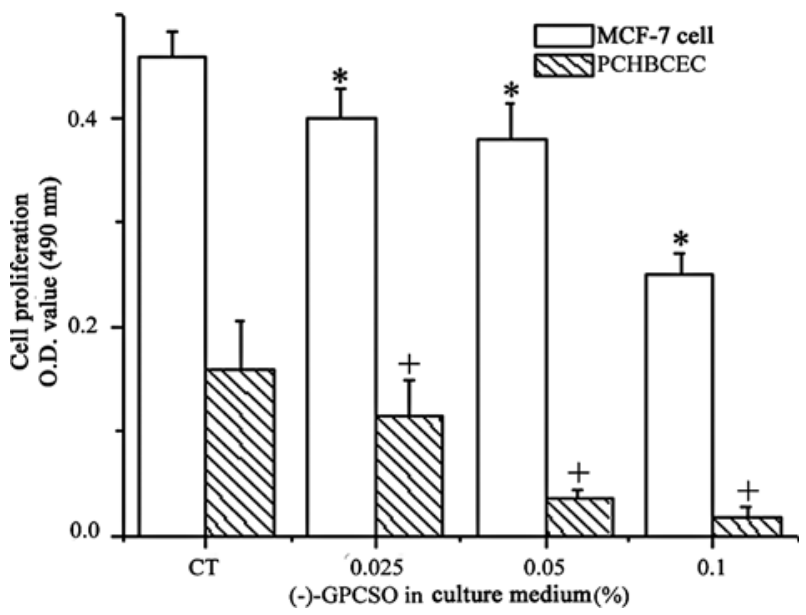

Figure 1. Inhibitory effects of (-)-GPCSO on the proliferation of MCF-7 and PCHBCEC. MCF-7 cells or PCHBCEC $\left(5 \times 10^{3}\right.$ cells/well) were treated with (-)-GPCSO at $0,0.025,0.05$ and $0.1 \%$ for $24 \mathrm{~h}$. Each bar represents the mean \pm SD for 4 wells. ${ }^{*}+$ Significant differences in the growth of either MCF-7 cells or PCHBCEC compared to their respective control groups $(\mathrm{p}<0.05)$.
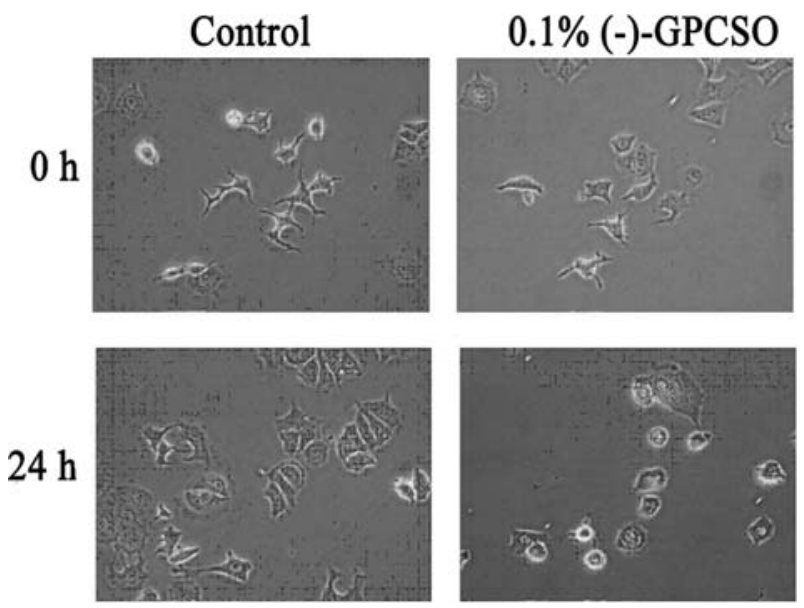

Figure 2. The morphology of MCF-7 cells after treatment with 0 and $0.1 \%$ (-)-GPCSO for 0 and $24 \mathrm{~h}$. After MCF-7 cells were treated with $0.1 \%$ of (-)-GPCSO for $24 \mathrm{~h}$, the cells appeared round and shrunken with loss of cell-to-cell contact. The nuclei of the cells were condensed and aggregated into dense compact masses as compared with the control cells (magnification, $\mathrm{x} 200)$.

(-)-GPCSO (0.05\%) contains $\sim 15 \mathrm{nM}(-)$-GP. These results suggest that (-)-GPCSO is a more potent inhibitor of human breast cancer cell proliferation. It was reported that the combination of (-)-GP with buthionine sulfoximine markedly inhibited the growth of MCF-7/Adr cells when compared with either inhibitor alone (38). Previous results from our laboratory revealed that the effective dose range for (-)-GPCSO against PC-3 cells, a prostate cancer cell line, was 524- to 2083-fold lower than that of chemically synthesized GP, which corresponds to an $\sim 361,500$ - to 454,240-fold lower amount than the FDA-mandated limit for GP content in human food (450 ppm) (unpublished data).

Cell morphology. It was reported that 50-100 $\mu \mathrm{M} \mathrm{GP}$ significantly induced apoptosis by $56-70 \%$ in lymphocytes

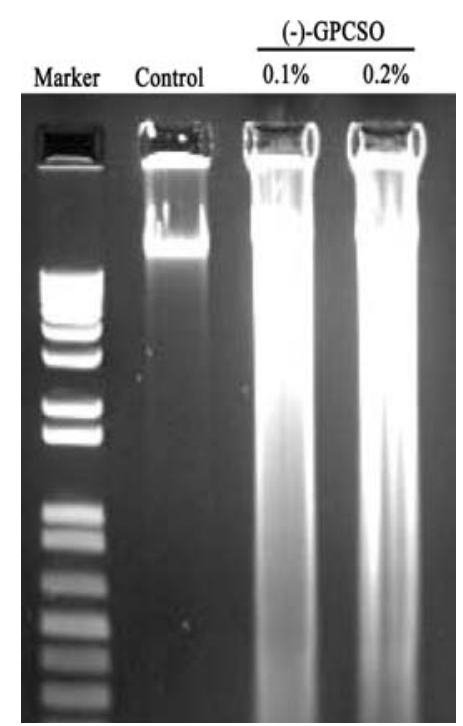

Figure 3. Agarose gel electrophoresis of DNA fragments from MCF-7 cells after treatment with (-)-GPCSO for $24 \mathrm{~h}$. Cells were treated with $0.1 \%$ DMSO, or 0.1 and $0.2 \%$ (-)-GPCSO for $24 \mathrm{~h}$. (-)-GPCSO at $0.2 \%$ induced internucleosomal DNA fragmentation of MCF-7 cells.

(37). Cell morphology was evaluated under a microscope after treatment with $0.1 \%$ of (-)-GPCSO for $24 \mathrm{~h}$. MCF-7 cells in the treatment group were shrunken and round in shape with condensed nuclei. In addition, cell-to-cell contact was lost. The percentage of abnormal cells was much larger in the $0.1 \%(-)$-GPCSO-treated group compared with the vehicle-treated group (Fig. 2).

DNA fragmentation analysis. Konac and his colleagues claimed that 50 and $75 \mu \mathrm{M}$ of GP induced DNA fragmentation in the human epidermoid laryngeal carcinoma cell line (HEp-2) after $6 \mathrm{~h}$ of exposure (39). We analyzed internucleosomal DNA fragmentation induced by (-)-GPCSO in MCF-7 cells using the Quick Apoptotic DNA Ladder Detection Kit. After a $24 \mathrm{~h}$ treatment, the vehicle control had no low molecular weight DNA, whereas, MCF-7 cells treated with 0.1 and $0.2 \%(-)$-GPCSO showed evidence of DNA fragmentation, a hallmark of apoptosis, that appeared after $24 \mathrm{~h}$ of exposure (Fig. 3).

(-)-GPCSO suppresses Bcl-2 mRNA expression in MCF-7 cells and PCHBCEC. In our laboratory, Huang et al found that $5 \mu \mathrm{M}(-)-G P$ induced apoptosis in a prostate cancer cell line, DU-145, and decreased Bcl-2 and Bcl-xL mRNA expression (7). In order to determine whether (-)-GPCSO has a similar effect on human breast cancer cells, we evaluated Bcl-2 mRNA expression in MCF-7 cells and PCHBCEC by RTPCR after treatment with 0.05 and $0.1 \%$ (-)-GPCSO. Our results demonstrated that (-)-GPCSO reduced Bcl-2 mRNA expression by 79, and $98 \%$ in MCF-7 cells, and 60 and $93 \%$ in PCHBCEC at 0.05 and $0.1 \%(-)$-GPCSO after a $24 \mathrm{~h}$ treatment, as compared to their vehicle-treated groups (Fig. 4A and B).

(-)-GPCSO down-regulated Bcl-2 protein expression in $M C F-7$ cells and PCHBCEC. Xu and colleagues reported that (-)-GP inhibited $\mathrm{Bcl}-2$ and $\mathrm{Bcl}-\mathrm{xL}$ protein expression in 
A

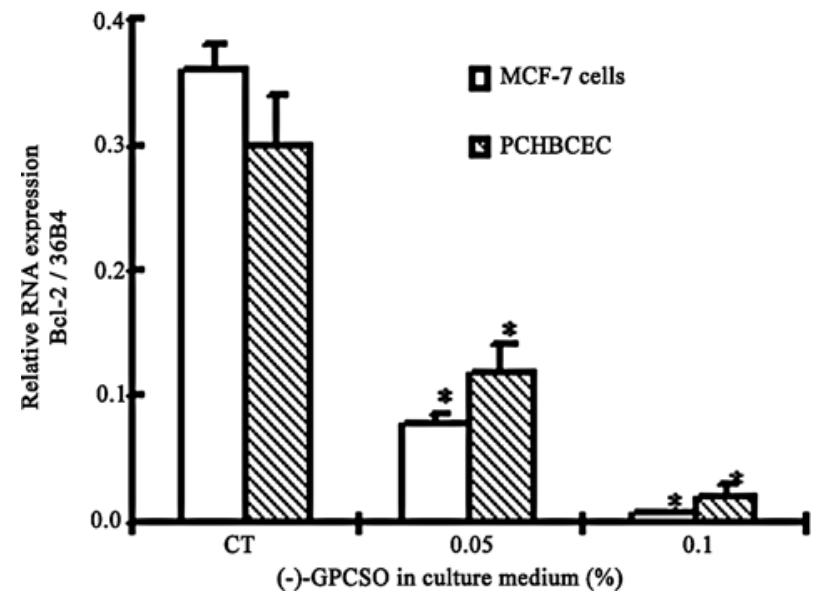

C

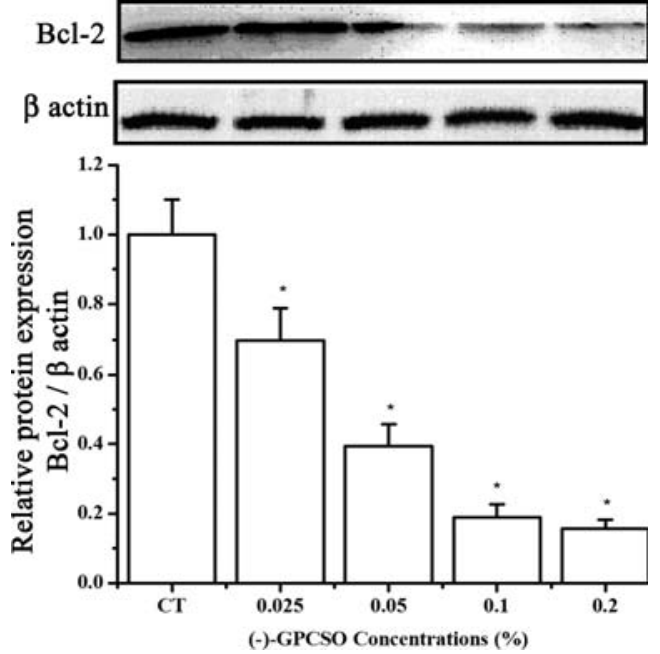

B

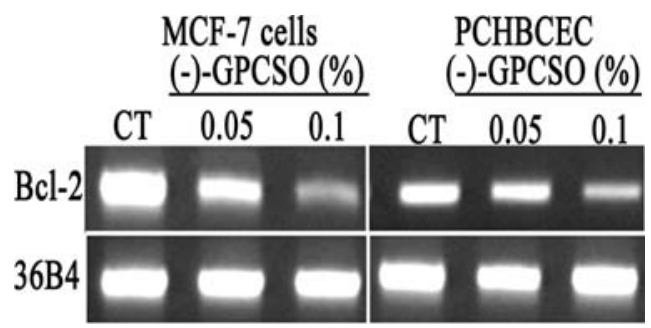

D

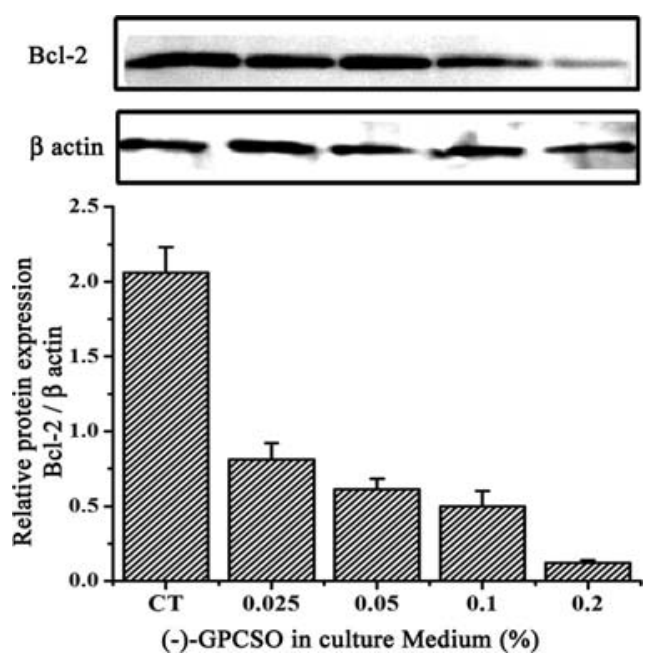

Figure 4. (A) Effects of 0.5 and 0.1\% (-)-GPCSO on Bcl-2 mRNA expression levels in MCF-7 cells and PCHBCEC. MCF-7 cells and PCHBCEC were treated with 0.05 and $0.1 \%$ (-)-GPCSO or vehicle for $24 \mathrm{~h}$. (-)-GPCSO decreased Bcl-2 mRNA expression in both MCF-7 cells and PCHBCEC in a dosedependent manner. *Statistically significant difference between (-)-GPCSO-treated groups and the vehicle-treated group. (B) Ethidium bromide-stained agarose gel of RT-PCR products from MCF-7 cells and PCHBCEC after treatment with 0.05 and $0.1 \%$ (-)-GPCSO for $24 \mathrm{~h}$. Agarose gel electrophoresis was performed as described in Materials and methods. Images were obtained using a UV transilluminator and the Fujifilm LAS-3000 image system. (C) (-)-GPCSO decreased Bcl-2 protein expression in MCF-7 cells. MCF-7 cells were treated with the desired concentrations of (-)-GPCSO for 24 h. (-)-GPCSO downregulated Bcl-2 protein expression in MCF-7 cells in a dose-dependent manner. ${ }^{*}$ Significant difference $(\mathrm{p}<0.05)$ from the control. (D) (-)-GPCSO downregulated Bcl-2 protein expression in PCHBCEC. Cells were treated with $0.025-0.2 \%$ of (-)-GPCSO or vehicle as control for $24 \mathrm{~h}$.

PC-3 cells, a human prostate cancer cell line, and enhanced radiation-induced apoptosis in PC-3 prostate cancer in vitro and in vivo without augmenting toxicity (31). Bcl-2 protein expression was measured by Western blot analysis after cells were treated with different concentrations of (-)-GPCSO for $24 \mathrm{~h}$. Our results revealed that (-)-GPCSO treatment decreased Bcl-2 protein expression in $\mathrm{MCF}-7$ cells and $\mathrm{PCHBCEC}$ in a dose-dependent manner. (-)-GPCSO at 0.025, 0.05, 0.1 and $0.2 \%$ decreased Bcl-2 protein expression by $38,65,82$, and 88\%, respectively, in MCF-7 cells (Fig. 4C), and 62, 71, 76, and $96 \%$, respectively, in PCHBCEC (Fig. 4D), as compared to their vehicle-treated groups.

\section{Discussion}

The aim of the current study was to investigate whether (-)-GPCSO inhibits growth and promotes the apoptosis of human breast cancer cells. We were able to evaluate the inhibitory effects of (-)-GPCSO on the growth of MCF-7 cells and PCHBCEC, and this inhibitory effect appeared to be mediated by the induction of apoptosis in both cell types. Cell morphology results showed that MCF-7 cells were shrunken and became round in shape. Meanwhile, the condensation and aggregation of the nuclear chromatin into dense masses beneath the nuclear membrane appeared after treatment with $0.1 \%$ (-)-GPCSO for $24 \mathrm{~h}$. The concentration of GP contained in (-)-GPCSO is much lower than that associated with the induction of apoptosis in human lymphocytes (37). This suggests that multiple components in (-)-GPCSO likely have a synergistic effect on the induction of apoptosis. Our results further illustrate that the apoptotic effect of (-)-GPCSO in breast cancer cells is mediated by the down-regulation of the Bcl-2 gene at both the mRNA and protein levels.

An understanding of the molecular mechanisms involved in the apoptosis induction and growth inhibition of (-)-GPCSO on 
breast cancer cells is limited. Researchers have found that GP induces apoptosis in HL-60 cells through a reactive oxygen species-independent mitochondrial dysfunction pathway (32). Chang et al reported that the apoptotic effect of GP in A549 cells, an alveolar cell carcinoma of the lung, was mediated via up-regulation of membrane-bound as well as soluble FasL in A549 cells (30). Research has shown that induction of apoptosis by GP involves the regulation of Bcl-2 family members, and one of the most important members is pro-apoptotic Bcl-2. Overexpression of Bcl-2 was shown by several researchers to accelerate tumorigenesis and confer resistance to various therapeutic agents (40-42). Bcl-2 also has an effect on the cell cycle, and this effect is independent of its anti-apoptotic function $(43,44)$. Studies have identified several mechanisms involved in the regulation of $\mathrm{Bcl}-2$ expression in different type of cells. It has been reported that deletion of the $\mathrm{BH} 4$ region and point mutations in $\mathrm{BH} 1$ and $\mathrm{BH} 2$ within Bcl-2 abrogate both its anti-apoptotic activity and its effect on the lymphocyte cell cycle (45). Pro-apoptotic $\mathrm{Bcl}-2$ family members include $\mathrm{Bcl}-2, \mathrm{Bcl}-\mathrm{xL}$, and $\mathrm{Bcl}-\mathrm{w}$; there are four regions (BH1-4) that are most highly conserved among these members. $\mathrm{BH} 1, \mathrm{BH} 2$ and $\mathrm{BH} 3$ form a hydrophobic groove that can bind $\mathrm{BH} 3 \alpha$-helix of an interacting BH-3 only relative (46). Several researchers have proposed that certain small molecules, such as Bax, Bad, and Bcl-xL, with BH3-binding pocket affinity might function as Bcl-2 or $\mathrm{Bcl}-\mathrm{xL}$ antagonists by blocking the heterodimerization of Bcl-2 or Bcl-xL $(47,48)$. Oliver et al found that (-)-GP binds to the $\mathrm{BH} 3$ binding groove of $\mathrm{Bcl}-\mathrm{xL}$ and $\mathrm{Bcl}-2$ and results in the inhibition of Bcl-2 and Bcl-xL function (33). Treatment of MCF-7 cells with basic fibroblast growth factor greatly decreases Bcl-2 protein and mRNA levels (49). As an important tumor suppressor gene, p53, not only regulates the cell cycle, but also modulates Bcl-2 protein activity (50). Aromatase inhibitors also can decrease $\mathrm{Bcl}-2$ protein expression (12). However, the regulation of Bcl-2 in cancer cells in vitro and in vivo is far from well understood. Much research is still needed in this area.

In conclusion, our findings revealed that (-)-GPCSO has inhibitory effects on breast cancer cell growth, in part, due to the down-regulation of Bcl-2 gene expression at both the mRNA and protein levels, thus inducing apoptosis. The results suggest that (-)-GPCSO could be developed as a potent, less toxic chemotherapeutic agent, or used in conjunction with conventional chemotherapeutic agents to improve the efficacy of treatment in breast cancer patients.

\section{Acknowledgements}

We thank Dr Kathleen Hayes for reading the manuscript and the helpful comments; Dr Rikihisa and Dr Colitz for providing photodocumentation equipment. This study was supported by the Department of Defense Breast Cancer Research Program Grants: DOD-DAMD 8140, 0319 and 9341.

\section{References}

1. Jemal A, Siegel R, Ward E, et al: Cancer statistics, 2008. CA Cancer J Clin 58: 71-96, 2008.

2. Edwards DR: TIMP-3 and endocrine therapy of breast cancer: an apoptosis connection emerges. J Pathol 202: 391-394, 2004.
3. Thompson CB: Apoptosis in the pathogenesis and treatment of disease. Science 267: 1456-1462, 1995.

4. Hoffman B and Liebermann DA: Molecular controls of apoptosis: differentiation/growth arrest primary response genes, proto-oncogenes, and tumor suppressor genes as positive \& negative modulators. Oncogene 9: 1807-1812, 1994.

5. Pardo OE, Lesay A, Arcaro A, et al: Fibroblast growth factor 2mediated translational control of IAPs blocks mitochondrial release of Smac/DIABLO and apoptosis in small cell lung cancer cells. Mol Cell Biol 23: 7600-7610, 2003.

6. Verheij $\mathrm{M}$ and Bartelink H: Radiation-induced apoptosis. Cell Tissue Res 301: 133-142, 2000.

7. Huang YW, Wang LS, Chang HL, et al: Molecular mechanisms of (-)-gossypol-induced apoptosis in human prostate cancer cells. Anticancer Res 26: 1925-1933, 2006.

8. Schafer ZT, Parrish AB, Wright KM, et al: Enhanced sensitivity to cytochrome c-induced apoptosis mediated by PHAPI in breast cancer cells. Cancer Res 66: 2210-2218, 2006.

9. Nagarkatti N and Davis BA: Tamoxifen induces apoptosis in Fas+ tumor cells by upregulating the expression of Fas ligand. Cancer Chemother Pharmacol 51: 284-290, 2003.

10. Zhang GJ, Kimijima I, Onda M, et al: Tamoxifen-induced apoptosis in breast cancer cells relates to down-regulation of bcl-2, but not bax and bcl-X(L), without alteration of p53 protein levels. Clin Cancer Res 5: 2971-2977, 1999.

11. Kellen JA: Raloxifene. Curr Drug Targets 2: 423-425, 2001.

12. Thiantanawat A, Long BJ and Brodie AM: Signaling pathways of apoptosis activated by aromatase inhibitors and antiestrogens. Cancer Res 63: 8037-8050, 2003.

13. Tsujimoto Y, Gorham J, Cossman J, Jaffe E and Croce CM: The $\mathrm{t}(14 ; 18)$ chromosome translocations involved in B-cell neoplasms result from mistakes in VDJ joining. Science 229: 1390-1393, 1985 .

14. Hockenbery D, Nunez G, Milliman C, Schreiber RD and Korsmeyer SJ: Bcl-2 is an inner mitochondrial membrane protein that blocks programmed cell death. Nature 348: 334-336, 1990.

15. Ricca A, Biroccio A, Del Bufalo D, Mackay AR, Santoni A and Cippitelli M: Bcl-2 over-expression enhances NF-kappaB activity and induces mmp-9 transcription in human MCF-7 (ADR) breast-cancer cells. Int J Cancer 86: 188-196, 2000.

16. Fahy BN, Schlieman MG, Mortenson MM, Virudachalam S and Bold RJ: Targeting BCL-2 overexpression in various human malignancies through NF-kappaB inhibition by the proteasome inhibitor bortezomib. Cancer Chemother Pharmacol 56: 46-54, 2005.

17. Aloj L, Zannetti A, Caraco C, Del Vecchio S and Salvatore M: Bcl-2 overexpression prevents $99 \mathrm{mTc}-\mathrm{MIBI}$ uptake in breast cancer cell lines. Eur J Nucl Med Mol Imaging 31: 521-527, 2004.

18. Kim R, Emi M, Tanabe K and Toge T: Therapeutic potential of antisense $\mathrm{Bcl}-2$ as a chemosensitizer for cancer therapy. Cancer 101: 2491-2502, 2004.

19. Nahta R, Yuan LX, Fiterman DJ, et al: B cell translocation gene 1 contributes to antisense Bcl-2-mediated apoptosis in breast cancer cells. Mol Cancer Ther 5: 1593-1601, 2006.

20. Gibson LF, Fortney J, Magro G, Ericson SG, Lynch JP and Landreth KS: Regulation of BAX and BCL-2 expression in breast cancer cells by chemotherapy. Breast Cancer Res Treat 55: 107-117, 1999.

21. Adams R, Geissman TA and Edwards JD: Gossypol, a pigment of cottonseed. Chem Rev 60: 555-574, 1960.

22. Anonymous: Gossypol - a new antifertility agent for males. Gynecol Obstet Invest 10: 163-176, 1979.

23. Liu S, Kulp SK, Sugimoto Y, et al: The (-)-enantiomer of gossypol possesses higher anticancer potency than racemic gossypol in human breast cancer. Anticancer Res 22: 33-38, 2002 .

24. Reddy RM, Changamma C, Reddanna P and Govindappa S: In vitro effects of gossypol and lactic acid on rat uterus and ovary during implantation and antiimplantation. Indian J Exp Biol 27: 1017-1019, 1989.

25. Jiang J, Sugimoto Y, Liu S, et al: The inhibitory effects of gossypol on human prostate cancer cells - PC3 are associated with transforming growth factor beta1 (TGFbeta1) signal transduction pathway. Anticancer Res 24: 91-100, 2004.

26. Zhang M, Liu H, Guo R, et al: Molecular mechanism of gossypol-induced cell growth inhibition and cell death of HT-29 human colon carcinoma cells. Biochem Pharmacol 66: 93-103, 2003. 
27. Teng CS: c-fos protein expression in apoptotic rat spermatocytes induced by gossypol. Contraception 57: 281-286, 1998.

28. Wang X, Wang J, Wong SC, et al: Cytotoxic effect of gossypol on colon carcinoma cells. Life Sci 67: 2663-2671, 2000.

29. Yurtcu E, Ergun MA and Menevse A: Apoptotic effect of gossypol on human lymphocytes. Cell Biol Int 27: 791-794, 2003.

30. Chang JS, Hsu YL, Kuo PL, Chiang LC and Lin CC: Upregulation of Fas/Fas ligand-mediated apoptosis by gossypol in an immortalized human alveolar lung cancer cell line. Clin Exp Pharmacol Physiol 31: 716-722, 2004.

31. Xu L, Yang D, Wang S, et al: (-)-Gossypol enhances response to radiation therapy and results in tumor regression of human prostate cancer. Mol Cancer Ther 4: 197-205, 2005

32. Hou DX, Uto T, Tong X, et al: Involvement of reactive oxygen species-independent mitochondrial pathway in gossypolinduced apoptosis. Arch Biochem Biophys 428: 179-187, 2004.

33. Oliver CL, Bauer JA, Wolter KG, et al: In vitro effects of the BH3 mimetic, (-)-gossypol, on head and neck squamous cell carcinoma cells. Clin Cancer Res 10: 7757-7763, 2004.

34. Hu YF, Chang CJ, Brueggemeier RW and Lin YC: Presence of antitumor activities in the milk collected from gossypol-treated dairy cows. Cancer Lett 87: 17-23, 1994.

35. Health of Population and Public Health Service in Uzbekistan in 1997, Tashkent, 1998

36. Statistics of Cancer in Russia and New Independent States of former USSR, 1991.

37. Ergun U, Yurtcu E and Ergun MA: Protective effect of ginkgo biloba against gossypol-induced apoptosis in human lymphocytes. Cell Biol Int 29: 717-720, 2005.

38. Liang XS, Rogers AJ, Webber CL, et al: Developing gossypol derivatives with enhanced antitumor activity. Invest New Drugs 13: 181-186, 1995 .

39. Konac E, Ekmekci A, Yurtcu E and Ergun MA: An in vitro study of cytotoxic effects of gossypol on human epidermoid larynx carcinoma cell line (HEp-2). Exp Oncol 27: 81-83, 2005.
40. Reszec J, Sulkowska M, Famulski W, Guzinska-Ustymowicz K and Sulkowski S: The expression of tumorigenesis markers in oral papilloma. Pol J Pathol 53: 195-200, 2002.

41. Adams JM, Harris AW, Strasser A, Ogilvy S and Cory S: Transgenic models of lymphoid neoplasia and development of a pan-hematopoietic vector. Oncogene 18: 5268-5277, 1999.

42. Reed JC, Kitada S, Takayama S and Miyashita T: Regulation of chemoresistance by the bcl-2 oncoprotein in non-Hodgkin's lymphoma and lymphocytic leukemia cell lines. Ann Oncol 5 (Suppl 1): 61-65, 1994.

43. Huang DC, Cory S and Strasser A: Bcl-2, Bcl-XL and adenovirus protein E1B19kD are functionally equivalent in their ability to inhibit cell death. Oncogene 14: 405-414, 1997.

44. Huang DC, O'Reilly LA, Strasser A and Cory S: The antiapoptosis function of Bcl-2 can be genetically separated from its inhibitory effect on cell cycle entry. EMBO J 16: 4628-4638, 1997.

45. O'Reilly LA, Huang DC and Strasser A: The cell death inhibitor Bcl-2 and its homologues influence control of cell cycle entry. EMBO J 15: 6979-6990, 1996.

46. Sattler M, Liang H, Nettesheim D, et al: Structure of Bcl-xL-Bak peptide complex: recognition between regulators of apoptosis. Science 275: 983-986, 1997.

47. Wang JL, Liu D, Zhang ZJ, et al: Structure-based discovery of an organic compound that binds $\mathrm{Bcl}-2$ protein and induces apoptosis of tumor cells. Proc Natl Acad Sci USA 97: 7124-7129, 2000.

48. Degterev A, Lugovskoy A, Cardone M, et al: Identification of small-molecule inhibitors of interaction between the $\mathrm{BH} 3$ domain and Bcl-xL. Nat Cell Biol 3: 173-182, 2001.

49. Wang $\mathrm{Q}$, Maloof $\mathrm{P}$, Wang $\mathrm{H}$, et al: Basic fibroblast growth factor downregulates $\mathrm{Bcl}-2$ and promotes apoptosis in MCF-7 human breast cancer cells. Exp Cell Res 238: 177-187, 1998.

50. Haldar S, Negrini M, Monne M, Sabbioni S and Croce CM: Down-regulation of bcl-2 by p53 in breast cancer cells. Cancer Res 54: 2095-2097, 1994. 